\title{
A inefetividade de direitos fundamentais decorrente da inacessibilidade da justiça
}

\author{
Vitor Alves Carvalho Fernandes ${ }^{1}$ \\ Mariana Gomes Lima² \\ Luciano de Oliveira Soura Tourinho ${ }^{3}$
}

\begin{abstract}
Resumo: A Justiça é a base de uma sociedade e sem ela não há a efetivação de Direitos e Garantias Fundamentais, pois é por meio dela que se obtém a equidade entre os membros da sociedade sem distinção de qualquer natureza. No Estado Democrático de Direito, com a Constituição da República Federativa do Brasil de 1988 houve a introdução da ideia de que a sociedade deve ser justa e igualitária, trazendo assim, compreensão do acesso amplo à Justiça, como forma de igualdade. Para Hans Kelsen (1988), a justiça provém da norma efetiva e aplicada, característica esta dificilmente vista nos dias atuais. Existem diversos obstáculos, de diversas naturezas, que dificultam o alcance à justiça, o que demonstra a seletividade que existe na efetivação do seu acesso. $\mathrm{O}$ estudo do tema será realizado por meio de pesquisas bibliográficas, cuja metodologia do estudo caracteriza-se como sendo do tipo 'indutivo', com o desenvolvimento de pesquisa qualitativa, de natureza exploratória, em virtude de suas finalidades. Com este trabalho, objetiva-se provocar a reflexão da comunidade jurídica a respeito da necessidade da promoção da acessibilidade à justiça e do estímulo à participação da comunidade na construção social. Desta forma, o Judiciário atua como um defensor do Estado em sua condição de omissão, e não dos Direitos Humanos, o que gera como resultado a legitimação do desrespeito ao Estado Democrático de Direito, em razão do descumprimento do ordenamento jurídico local, que prevê a igualdade material e a dignidade da pessoa humana, bem como a efetivação da cidadania.
\end{abstract}

Palavras-chave: Equidade. Acesso à justiça. Estado democrático de direito. Garantias fundamentais.

Abstract: Justice is the basis of society and without it that is no effectiveness of the Fundamental Rights and guarantees, because it's through it that it is possible to obtain equity among the members of the society without distinction of any kind. At the Democratic State of Law, with Federative Republic of Brazil's Constitution of 1988 there was the introduction of the idea that society must be fair and egalitarian, bringing the knowledge about the broad access to the Justice, as a form of equality. For Hans Kelsen (1988), justice comes from the effective and applied norm, characteristics that are hardly seen currently. There are several obstacles, of many roots, that difficult the reaching of justice, which demonstrates the selectivity that exists in the effectiveness of access to Justice. The study of the theme will be carried out through bibliographical research. Thus, it's methodology is characterized as being of the inductive type, with the development of qualitative research, of exploratory nature, due to its purposes. The objective of this work is to induce the Law community's reflection regarding the need to promote accessibility to Justice and to encourage citizens' participation in social construction. Thus, the Judiciary Power appears as a State's defender in its condition of omission, and not of

\footnotetext{
${ }^{1}$ Bacharelando em Direito pela Faculdade Independente do Nordeste (FAINOR). E-mail: vitorluis18@hotmail.com.

2 Bacharelanda em Direito pela Universidade Estadual do Sudoeste da Bahia (UESB). Membro do Núcleo de Direito Contemporâneo da UESB. Membro do grupo de pesquisa Culpabilidade, Vulnerabilidade e Seletividade Penal (CNPq). Email: mariana.glima31@gmail.com.

3 Advogado. Doutor em Direito Público - Direito Penal pela Universidade Federal da Bahia. Mestre em Direito Público Direito Penal pela Universidade Federal da Bahia. Professor auxiliar da Universidade Estadual do Sudoeste da Bahia. Professor da Faculdade Independente do Nordeste. Coordenador do Núcleo de Estudos de Direito Contemporâneo da UESB. Coordenador do grupo de pesquisa Culpabilidade, Vulnerabilidade e Seletividade Penal (CNPq). E-mail: luciano.oliveira.jus@hotmail.com.
}

Página 151 Caderno de Ciências Sociais Aplicadas, Vitória da Conquista/BA, vol. 15, nº 26, ano 15, p. 151-167, jul/dez 2018. 
Human Rights. Therefore, it is possible to realize the disrespect to Democratic State of Law, due to noncompliance with the local legal system, which provides for material equality and dignity of the human person, as well as the effectiveness of citizenship.

Keywords: Equity; Access to Justice; Democratic State of Law; Fundamental Guarantees.

\section{Introdução}

A concepção de justiça sempre foi elemento de investigação teórica, em uma nítida tentativa de objetivar conceitos de ordem subjetiva. Sua percepção trilha no sentido de reconhecer influência de institutos metajurídicos, como substrato de fundamentação. Nesse aspecto, a justiça passa a ser interpretada a partir de critérios de igualdade material, em uma significação de concretude.

O acesso à justiça, por volta dos séculos XVIII e XIX, era tido como um direito natural, sendo prescindível a intervenção do Estado para sua concretização. Este existe antes do Estado, porém, na prática, somente quem ingressava com ação tinha este direito protegido, e, de forma incoerente, só os mais afortunados podiam acessar tal medida.

Tal fato traz a ideia de um sistema inacessível à população como um todo, tendo em vista que os pobres não tinham a capacidade de ingresso no sistema judiciário, devido sua difícil acessibilidade que privilegiava aqueles que possuíam mais renda, em virtude dos altos custos relativos ao acesso a uma prestação jurisdicional. Até mesmo o estudo jurídico era algo indiferente ao acesso à justiça, com enfoque, apenas, no estudo dogmático e formal, sem qualquer preocupação com a capacidade de inteligibilidade da sociedade, bem como com a necessidade de garantia de seus direitos.

Nesse panorama, reconhecer a importância do estudo dos obstáculos ao acesso à justiça baliza a própria necessidade de concretizá-la, a partir da promoção de direitos relativos à educação e à ampliação das vias de solução de conflito. A democratização da educação de qualidade, a mudança paradigmática no ensino jurídico, com uma informalização e simplificação da linguagem jurídica, bem como a criação de núcleos alternativos de resolução de conflitos constituem um mote de propostas para efetivação do acesso à justiça e, consequencialmente, da realização de direitos fundamentais.

O presente artigo será norteado pelo método exploratório, com uma abordagem críticoreflexiva. Sua proposta dialógica fornecerá elementos para uma análise da problemática do acesso à justiça, a partir da investigação da literatura construída entre os clássicos e os teóricos contemporâneos. Sua sistematização e estruturação permitirão o acesso ao conhecimento relativo aos conceitos de justiça

Página 152 Caderno de Ciências Sociais Aplicadas, Vitória da Conquista/BA, vol. 15, n 26, ano 15, p. 151-167, jul/dez 2018. 
e acesso à justiça, os obstáculos à sua realização e as propostas para sua efetivação no contexto social moderno.

\section{Aspectos conceituais e evolutivos relativos ao acesso à justiça}

A conceituação de determinados institutos jurídicos, relativos às regras ou princípios, apresenta com uma importância singular para que se possa compreender por completo o estudo do presente artigo. Nesse sentido, revela-se com relevância o conceito de justiça que, de acordo com Aristóteles (1996, p. 193), trata-se de uma disposição relacionada ao caráter que é a "disposição da alma que graças à qual elas dispõem a fazer o que é justo, a agir justamente e a desejar o que é justo; de maneira idêntica, diz-se que a injustiça é a disposição da alma de graças à qual elas agem injustamente e desejam o que é injusto".

Ao longo do tempo, a definição de justiça foi sendo delineada de acordo com cada contexto vivenciado. Com o crescimento da população, os direitos foram se tornando mais coletivos e assim, fundou-se uma compreensão mais humanística sobre o indivíduo e, consequentemente, o acesso a uma justiça mais efetiva foi tornando-se necessário, "uma vez que a titularidade de direitos é destituída de sentido, na ausência de mecanismos para sua efetivação". (CAPPELLETTI, 1988, p.5)

Para que essa efetivação seja, de fato, concretizada em seu sentido amplo, faz-se necessário a utilização de um sistema acessível, no qual, de acordo com a doutrina, o cidadão não possua somente acesso as cortes, sendo imprescindível, segundo Paroski (2006, p.198):

[...] obter concretamente a tutela jurisdicional buscada e, além disso, não importa unicamente em alcançar solução jurisdicional para os conflitos de interesses, mas sim, colocar o ordenamento jurídico à disposição das pessoas outras alternativas como meios para esta solução, a exemplo da mediação e da arbitragem privadas. Significa romper barreiras e introduzir mecanismos de facilitação não apenas do ingresso em juízo, mas também durante todo o desenvolvimento do procedimento jurisdicional, significa redução de custos, encurtamento de distâncias, duração razoável do processo, diminuição de recursos processuais e efetiva participação na relação processual, dentre tantos aspectos que podem ser ressaltados. (PAROSKI, 2006, p.198)

Página 153 Caderno de Ciências Sociais Aplicadas, Vitória da Conquista/BA, vol. 15, n 26, ano 15, p. 151-167, jul/dez 2018. 
Com isso, o acesso à justiça terá produção de efeitos individual e socialmente justos, pois, como mencionado, após uma ação judicial o autor deve sair em condições melhores do que entrou, devido ao simples fato de ter seus direitos deturbados, e após a ação não mais. Além disso, há também os direitos coletivos, decorrentes das relações sociais, que com o acesso à justiça, seguindo um sistema acessível e eficaz, serão devidamente garantidos, trazendo uma qualidade social melhor, a exemplo da dignidade da pessoa humana. Sua garantia, por meio da justiça acessível, traz uma qualidade de vida significativamente mais estruturada para a população como um todo, fato este que não ocorre com um sistema judiciário inacessível, devido ás custas, à morosidade, entre outros fatores.

A definição de acesso à justiça não é estática, mas dinâmica, sendo adaptada de acordo com o contexto experimentado, a interpretação da sociedade e juntamente com a de seus governantes e o avanço dos estudos no âmbito jurídico. Nos séculos dezoito e dezenove, na vigência do Estado Liberal, presenciou-se a ascensão da burguesia e o crescimento da importância do mercado. Surge então, o Liberalismo Econômico, que pregou um mercado autorregulado e considerou a intervenção estatal na economia como prejudicial, noção que deu origem ao Liberalismo Jurídico, cujo foco está na existência de um Estado que garanta os direitos dos indivíduos contra a intervenção arbitrária dos governantes.

Segundo Moraes (2014, p. 271), a Revolução Francesa exerceu grande influência no surgimento do pensamento liberal e seu modelo de Estado. A revolução foi conduzida a efeito, principalmente, pelas camadas sociais menos favorecidas, os camponeses e pobres, associados à emergente burguesia. Porém, inicialmente, os resultados da Revolução Francesa contemplaram a classe burguesa: os comerciantes e os proprietários de terras, e desta realidade, a burguesia buscou a manutenção, a fim de que a justiça social almejada pelo campesinato e pelos sans-cullotes não fosse realizada, pois poderia implicar em antagonismos em relação aos seus interesses.

Os ideais de solidariedade, segurança e legalidade não se concretizaram. Notava-se uma visão mais individualista de justiça. O pensamento vigente era o de que, embora o acesso à justiça fosse um direito natural, este não necessitava da intervenção estatal para sua garantia. Desta maneira, o Estado permanecia em condição de passividade quanto a problemas, como a falta de aptidão de um cidadão para reconhecer os seus direitos e agir de modo que os efetivasse. De forma, consectária, o acesso pleno à justiça não ficava ao alcance das classes sociais menos favorecidas, de acordo com Cappelletti e Garth (1998, p. 3). A justiça, assim como mercadorias, só podia ser alcançada por aqueles que possuíssem poderio econômico para arcar com o seu custo. Assim, percebe-se apenas a presença da igualdade formal de acesso. À luz dos ensinamentos de Cappelletti e Garth (1998, p. 4), tem-se que:

Página 154 Caderno de Ciências Sociais Aplicadas, Vitória da Conquista/BA, vol. 15, nº 26, ano 15, p. 151-167, jul/dez 2018. 
À medida que as sociedades do laissez-faire [grifo nosso] cresceram em tamanho e complexidade, o conceito de direitos humanos começou a sofrer uma transformação radical. A partir do momento em que as ações e relacionamentos assumiram, cada vez mais, caráter mais coletivo que individual, as sociedades modernas necessariamente deixaram para trás a visão individualista dos direitos, refletida nas "declarações de direitos", típicas dos séculos dezoito e dezenove. (CAPPELLETTTI; GARTH, 1998, p. 4)

Os direitos e deveres sociais passaram a ser reconhecidos, sejam eles da comunidade, do governo, das associações ou dos indivíduos. Segundo Cappelletti e Garth (1998, p. 4), esse novo reconhecimento dos direitos teve a importância de tornar efetivas as garantias dos seres humanos, e podem ser exemplificados no preâmbulo Constituição Francesa de 1946. Exemplos de tais garantias são as medidas de seguridade social, além da expansão do sistema de saúde para abranger mais cidadãos. Este texto reafirma, bem como renova os direitos humanos e inalienáveis, ademais, reitera a isonomia entre homens e mulheres e os princípios políticos, econômicos e sociais. Desta forma, passou-se a reconhecer a importância do efetivo acesso à justiça.

Surgiram críticas ao modelo liberal, que atuava de forma a promover a concentração de riquezas garantias aos burgueses. Conforme lições de Bonavides (2007, p. 186), as massas passaram a reivindicar direitos sociais, trabalhistas e previdenciários. Houve, assim, o fortalecimento das organizações operárias, que contribuiu com a ideia da plena participação política dos diversos segmentos da sociedade. Desenvolveu-se, então, no século XX, o Estado Social, como produto deste clamor popular, para superar o neutralismo e o formalismo do Estado Liberal, como aduz Silva (1999, p. 119).

O surgimento do Estado do Bem-Estar Social se deu devido à necessidade da maior intervenção estatal em diversos âmbitos da sociedade, para promover o acúmulo de capital. Afirma Grau (2002, p. 28) que a extensão das funções estatais não se limita a garantir o desenvolvimento econômico, pois a ela se adiciona o desenvolvimento social. Houve, dessa forma, o progresso do Estado Democrático de Direito, que reside no ideal de efetivação destas promessas voltadas à promoção da igualdade material. O seu progresso deve ser analisado no âmbito da evolução do Estado Liberal ao Estado Social, o que conduziu à adição e subtração de determinados elementos da definição de Estado. "No Estado Democrático de Direito há um elemento revolucionário de transformação do

Página 155 Caderno de Ciências Sociais Aplicadas, Vitória da Conquista/BA, vol. 15, n² 26, ano 15, p. 151-167, jul/dez 2018. 
status quo" (SILVA, 1999. p. 123). Houve uma inclusão da democracia e da soberania popular de significativa importância histórica.

Segundo Moraes (2014, p. 278), “o grande desafio do Estado Democrático de Direito seria impedir que as suas funções sociais se transformassem em funções de dominação, em vista do poderio que atribuem à máquina estatal", afinal, correr-se-ia o risco de as entidades de governo utilizarem as garantias como moeda de troca, a fim de se garantir a manutenção do poder perante a sociedade.

A atuação do Estado Democrático de Direito consiste em inserir a lei fundamental do Estado Democrático nas estratégias de justiça política. Desta forma, estimula-se a tomada de medidas distributivas e estabelece-se limitações de poder. As leis às quais o Estado se submete levam em conta as desigualdades sociais existentes para que se promova transformação social. Aqui reside a mudança de status quo.

A relação de superioridade entre a Constituição e as leis é percebida como uma ferramenta de efetivação da essência do Estado Democrático de Direito: a justiça social e a isonomia, pois apenas se pode legislar a respeito daquilo que é permitido na Carta Magna. Esta é uma estratégia de limitação do legislador para que este não se utilize da sua posição dotada de poder para legislar sobre interesses que concernem apenas à sua vontade ou à vontade de um determinado grupo, ferindo a igualdade entre os cidadãos. Surge, nesse aspecto, a classificação de Constituição dirigente, por conta da assunção de papel balizador, vinculante da Constituição Federal em relação à legislação.

Streck e Morais (2004, p. 93) afirmam que estes são os princípios regentes do Estado Democrático de Direito, em que se percebe um maior reconhecimento da necessidade da promoção ao acesso à justiça pela sociedade:

Constitucionalidade: vinculação do Estado Democrático de Direito a uma Constituição como instrumento básico de garantia jurídica; Organização democrática da sociedade; Sistema de direitos fundamentais individuais e coletivos, seja como Estado de distância, porque os direitos fundamentais asseguram ao homem uma autonomia perante os poderes públicos, seja como um Estado antropologicamente amigo, pois respeita a dignidade da pessoa humana e empenha-se na defesa e garantia da liberdade, da justiça e da solidariedade; Justiça Social como mecanismos corretivos das desigualdades; Igualdade não apenas como possibilidade formal, mas, também, como articulação de uma sociedade justa; Divisão de Poderes ou de Funções; Legalidade que aparece como medida do direito, isto é, através de um meio de

Página 156 Caderno de Ciências Sociais Aplicadas, Vitória da Conquista/BA, vol. 15, n² 26, ano 15, p. 151-167, jul/dez 2018. 
ordenação racional, vinculativamente prescritivo, de regras, formas e procedimentos que excluem o arbítrio e a prepotência; Segurança e certeza jurídicas.

São estes os fundamentos que devem atuar como norte para a prática e efetivação da justiça, ao cumprirem o papel de regentes dos atos dos Poderes Executivo, Legislativo e Judiciário.

\section{Obstáculos ao acesso à justiça}

Ainda que, ao longo da história, tenha-se alcançado diversas conquistas, dentre elas, as importantes garantias trazidas pelo Estado Democrático de Direito, existem muitos obstáculos que impedem a sua efetivação e o alcance da justiça de forma isonômica. São eles das mais diversas origens, atingido amplamente as camadas menos favorecidas nos âmbitos econômico, intelectual ou de influências.

Uma dentre as principais características que dificultam o acesso à justiça é a linguagem inacessível, composta de palavras extremamente rebuscadas e em outros idiomas, como latim ou inglês, o que provoca restrições ao alcance da justiça, visto que não são todos que compreendem outras línguas além do português, em sua variação linguística coloquial, demonstrando uma falta de importância do Estado para com os que não receberam acesso a uma boa educação, indo de encontro ao princípio da isonomia, ao causar uma desigualdade social. A academia jurídica trata esta realidade de maneira negligente, marginalizando aqueles que tiveram acesso à educação de baixa qualidade. Nas lições de Oliveira e Tadielo (2016, p. 6):

$\mathrm{O}$ acesso à justiça pressupõe o entendimento de seu funcionamento e a compreensão das peças desta máquina administrativa que rege uma sociedade e, em consequência, a vida de cada um de seus membros, já que o homem encontra- se sempre em evolução e novas concepções de vida vão surgindo e requerendo procedimentos mais próximos e adaptados à realidade. Tal entendimento passa, assim, pela superação do entrave linguístico, pelo qual o seleto grupo que conhece mais que os caminhos e os atalhos desta linguagem deve se responsabilizar em nome da Constituição que rege o país, e dar condições ao povo de transcender os obstáculos do que lhes é direito. (OLIVEIRA; TADIELO, 2016, p.6) 
Este fato nos conduz a outro aspecto importante, relativo à educação de qualidade centralizada nas classes mais favorecidas socialmente, pois, infelizmente, o serviço escolar público fornecido pelo Estado brasileiro possui limitações, comumente evitadas nas escolas particulares, acessadas, apenas, por cidadãos de maior capacidade financeira. Esta disparidade pode ser notada, por exemplo, na ação trabalhista, em que a parte autora, em sua maioria, é menos favorecida financeira e, por consequência, intelectualmente, e a parte ré, na maior parte das vezes, é formada por pessoas com maior poder econômico e mais capacitação educacional, conhecendo mais seus direitos, o que proporciona a ciência de meios para conduzir o trâmite processual de forma favorável para si.

O pleito de uma causa judicial apresenta alto custo, o que prejudica e afasta a população de menor renda - que, no País, é maioria - do acesso a uma justiça efetiva, reforçando a percepção da falta de interesse do Estado em proporcionar essa acessibilidade. Ao estabelecer uma comparação com outros países, como Alemanha e Inglaterra, nota-se que estes perceberam, nos últimos anos, que esta parcela da população necessita de auxílio para ter seus direitos efetivados. Nos países acima citados, por exemplo, também não havia assistência gratuita, o Estado, assim como no Brasil, não tinha o interesse na promoção do acesso à justiça da população. Diante da situação, o governo passou a remunerar os advogados para fornecer aconselhamento jurídico e assistência judiciária. Desta forma preconizam Cappelletti e Garth (1998, p. 8):

Pessoas ou organizações que possuam recursos financeiros consideráveis a serem utilizados têm vantagens óbvias ao propor ou defender demandas. Em primeiro lugar, elas podem pagar para litigar. Podem, além disso, suportar as delongas do litígio . Cada uma dessas capacidades, em mãos d e uma única das partes, pode ser uma arma poderosa; a ameaça de litígio torna-se tanto plausível quanto efetiva. De modo similar, uma das partes pode ser capaz de fazer gastos maiores que a outra e, como resultado, apresentar seus argumentos de maneira mais eficiente. Julgadores passivos, apesar de suas outras e mais admiráveis características, exacerbam claramente esse problema, por deixarem às partes a tarefa de obter e apresentar as provas, desenvolver e discutir a causa dentro de "um prazo razoável" (22) é, para muitas pessoas, uma Justiça inacessível. (CAPPELLETTI; GARTH, 1998, p.8)

No Brasil, há a Defensoria Pública, que fornece assistência jurídica gratuita para os menos afortunados. No entanto, este órgão possui pouco contingente para atender a toda a população, de 
forma satisfativa. Assim, é de extrema importância e necessidade a existência e ajuda dos Juizados, que possuem prazos, custas e procedimentos diferentes do processo ordinário, instaurado na Justiça Comum. Os Juizados possuem, em tese, prazos mais céleres, custas menores e uma desnecessidade de advogado até a fase recursal. Tais medidas ajudam no acesso mais efetivo à Justiça, no entanto, assim como na Defensoria Pública, a quantidade de servidores é pequena para a demanda. Com isso, na atual realidade brasileira, o tempo de duração que era para ser menor, não o é. Como resultado, na maioria dos casos, os processos possuem prazos para prestação jurisdicional material superiores a mil dias, cerca de três anos.

Outro fator relevante é o acesso ao Juizado prescindindo do advogado. Observa-se que, mesmo se tratando de um processo mais célere e menos complexo, para aqueles sem formação na área do Direito, o Juizado ainda se mostra de difícil entendimento, o que traz prejuízos aos direitos das partes, visto que essas não compreendem as fases, os prazos, os procedimentos do Juizados Especiais, prejudicando seus direitos e garantias. Ao apresentarem uma demanda quando ingressam com a ação sem orientação de um advogado, dificilmente os servidores prestam o auxílio necessário ao cidadão. Por fim, mesmo que o Juizado seja uma alternativa de solução da dificuldade do acesso à justiça, poucas pessoas têm o conhecimento da existência desse instituto e, aqueles que sabem de sua existência não possuem a informação dos meios de como utilizá-lo. Segundo as lições de Mauro Capeletti (1998, p. 11):

(...) uma vez que litigantes de baixo nível econômico e educacional provavelmente não terão a capacidade de apresentar seus próprios casos, de modo eficiente, eles serão mais prejudicados que beneficiados (...). Sem alguns fatores de compensação, tais como um juiz muito ativo ou outras formas de assistência jurídica, os autores indigentes poderiam agora in tentar uma demanda, mas lhes faltaria uma espécie de auxilio que lhes pode ser essencial para que sejam bem sucedidos. (CAPPELLETTI, 1998, p. 11)

É notório que a precariedade escolar tem influência direta no acesso à justiça. Se a educação tivesse um melhor desenvolvimento, uma maior capacitação dos profissionais e uma melhor estrutura para os professores, a população teria mais conhecimento o que, claramente, traria benefícios para a questão do acesso à justiça. No entanto, é do interesse do Estado que a população não tenha educação e informação de qualidade, já que, desta forma, criam-se os currais eleitorais, ao manter o cidadão dependente dos supostos favores dos políticos, convertidos em promessas de votos. Além disto, o

Página 159 Caderno de Ciências Sociais Aplicadas, Vitória da Conquista/BA, vol. 15, n² 26, ano 15, p. 151-167, jul/dez 2018. 
Estado se beneficia da falta de informação dos cidadãos, a partir do momento em que cria uma prerrogativa para ações ilegais e antiéticas, em benefício pessoal dos detentores do poder, a exemplo da implementação de novos tributos, com fins distintos daqueles expressos no momento da sua criação.

A morosidade processual é fator de relevância no entrave ao devido acesso a justiça, ocasionado pelo despreparo dos servidores públicos, que não recebem uma formação profissional adequada, além de, na maioria das vezes, serem insatisfeitos com o trabalho por conta de atrasos salariais. Há, ainda, a falta de fiscalização pública da eficiência do trabalho desenvolvido, o que fomenta a sua realização de forma descuidada e prejudicial.

Não se pode olvidar, ainda, da atuação dos magistrados que, geralmente, são poucos para a demanda processual crescente, além da falta de comprometimento com o cargo, notada em grande parte desta categoria de profissionais, afinal, suas práticas não são devidamente fiscalizadas, tampouco, punidas quando necessário. Segundo Castelar Pinheiro (2003, p.39), a matriz do problema está em diversas origens:

[...] o número insuficiente de juízes, as muitas possibilidades existentes para se protelar uma decisão e o grande número de recursos possíveis a instâncias superiores. Em um segundo grupo, em ordem descendente de importância, os juízes incluem a falta de equipamentos de informática, a preferência dos advogados por estender a duração dos litígios, a falta de treinamento dos advogados, a ênfase excessiva no formalismo processual e a precária situação das instalações judiciárias. (CASTELAR PINHEIRO, 2003, p. 39).

Ainda, enfrenta-se o comportamento não colaborativo do advogado que se utiliza das prerrogativas legais, não em busca de um direito, mas com o intuito de prolongar o máximo possível a duração do trâmite processual, a fim de ganhar tempo para diminuir seus deveres e preparar a sua defesa, causando prejuízo à parte adversa. Nota-se, segundo Pinheiro (2003, p. 4-5):

[...] no que se refere ao caso brasileiro, é consensual que as deficiências do Judiciário decorrem de causas profundamente arraigadas [...] os problemas decorrentes dessa matriz histórica são acentuados pela instabilidade do arcabouço jurídico do país, pelo arcaísmo e excessivo formalismo dos códigos de processo e pela má formação de boa parte da magistratura e de todos aqueles que, mais amplamente, se poderia designar

Página 160 Caderno de Ciências Sociais Aplicadas, Vitória da Conquista/BA, vol. 15, n 26, ano 15, p. 151-167, jul/dez 2018. 
como "operadores do direito" [...] a lentidão e o caráter pesadamente burocrático e formalista de seu funcionamento teriam hoje a permanência praticamente de um traço cultural, com baixa probabilidade de mudança com base somente em fatores endógenos. Uma consequência da aceitação quase fatalista desse alegado traço cultural pelos magistrados e operadores do direito seria o excessivo recurso a argumentos processuais, em detrimento de decisões substantivas sobre o mérito das questões tendência esta que reforça a descrença de grande parte da sociedade quanto a resolver seus conflitos pela via judicial. (PINHEIRO, 2003, p. 4-5).

Ainda que tenha sido estabelecida a limitação dos poderes das autoridades, os cidadãos, por exemplo, ainda percebem os profissionais da área jurídica, principalmente magistrados, com olhar de temor. E esta relação não é unilateral, ao passo que os próprios profissionais impõem esta visão, como forma de manter determinado status, e muitas vezes utilizam o poder investido pelo cargo ocupado para cometer abusos raramente contestados.

Frente a todos estes obstáculos, nota-se a urgência de medidas que os ultrapassem, já que reformas estruturais, na conjuntura brasileira, são consideradas como utópicas. É preciso chamar a população para perto, que se mantém afastada e descrente no serviço público e dos poderes, pois não há transparência notável nem representação popular nos diversos estágios da construção dos atos dos Poderes Legislativo, Judiciário e Executivo.

\section{Necessidade de reconhecimento de outras formas de resolução de conflitos além das cortes}

Diante do presente contexto vivido, faz-se necessário reconhecer alternativas para de resolução de conflitos, aproximando os cidadãos do alcance à efetivação dos seus direitos. Ultimamente, tem-se decaído a valorização da postura advocatícia litigante, dando espaço ao pensamento de uma atuação jurídica colaborativa, que busca uma resolução, sem necessariamente precisar do juízo. É uma maneira de proporcionar ainda mais o acesso à justiça, como a utilização da conciliação, mediação e arbitragem, nas quais, com exceção desta, as partes em comum acordo encontram a melhor resolução do conflito. Nesse sentido, discute Dakolias apud Souza (2015, p.41) que:

Os meios alternativos de resolução de controvérsias [em inglês, ADR] estão se tornando cada vez mais populares na América Latina porque oferecem uma alternativa

Página 161 Caderno de Ciências Sociais Aplicadas, Vitória da Conquista/BA, vol. 15, n 26, ano 15, p. 151-167, jul/dez 2018. 
para os atrasos e corrupção que caracterizam o sistema judiciário. Ao mesmo tempo, o incremento desses aumenta o acesso à justiça para uma grande porcentagem da população. Isto tem sido especialmente importante para os mais pobres. Inicialmente, juízes e advogados podem sentir-se ameaçados por sua perda de poder devido às opções que passam a ser oferecidas aos litigantes. Os juízes podem encontrar consolo, contudo, no fato de que sua carga de trabalho fica reduzida em quantidade, além do que casos de grande complexidade e visibilidade são afastados do Judiciário. Embora os advogados também possam temer os meios alternativos porque eles requerem que eles adquiram novas habilidades e joguem sob novas regras, eles podem acabar percebendo que, a longo prazo, os meios alternativos são úteis não apenas para seus clientes como também para si mesmos. Em muitos casos, as partes se mostram mais propostas a cumprir acordos obtidos pela via da mediação do que decisões provenientes do Judiciário. (DAKOLIAS apud SOUZA, 2015, p. 41)

Estas alternativas contam, ainda, com um procedimento mais informal e mais célere, trazendo benefícios para ambas as partes, visto que será encontrado o ponto de equilíbrio entre suas vontades. A autotutela também é forma alternativa de resolução de conflitos, na qual a parte, unilateralmente, soluciona o problema. O maior exemplo de autotutela é a greve, que consiste na restrição unilateral do trabalho da parte, para que haja a busca de um direito.

Outro instituto é a autocomposição na qual as partes solucionam seu conflito sem intervenção alguma de terceiro. Há, ainda, a heterocomposição, que engloba as medidas anteriormente mencionadas: mediação, conciliação e arbitragem com o acréscimo da jurisdição. Neste método a solução do conflito se dá com o auxílio de terceiro. (SENA, 2007, p. 93-95)

Já a arbitragem ocorre quando as partes atribuem a um terceiro, em geral, escolhido por elas, denominado árbitro, a resolução do conflito. Nessa modalidade somente podem ser objetos do conflito direitos patrimoniais disponíveis. (SENA, 2007, p. 96) Já a mediação ocorre quando um terceiro auxilia as partes a encontrarem a solução ideal para ambos. O mediador, não impõe uma medida específica a ser tomada, mas mantém um diálogo para que elas encontrem uma solução satisfatória. De acordo Warat apud Menezes (2001, p. 63):

A mediação é uma forma ecológica de resolução dos conflitos sociais e jurídicos; uma forma na qual o intuito de satisfação do desejo substitui a aplicação coercitiva e

Página 162 Caderno de Ciências Sociais Aplicadas, Vitória da Conquista/BA, vol. 15, n² 26, ano 15, p. 151-167, jul/dez 2018. 
terceirizada de uma sanção legal. A mediação como uma forma ecológica de negociação ou acordo transformador das diferenças[...] A mediação começa quando as partes conseguem interpretar, no simbólico, ódios e amores que as diferenciam. A mediação facilita às partes a possibilidade de interpretar seus ódios e amores. O que é mediável são os conflitos de afetos, não as diferenças patrimoniais sem história, sem afetos, nem desejo (elas são transações que podem estar disfarçadas de mediações). Nos casos patrimoniais sem história, se decidem as diferenças, não existe conflito a resolver. Para que algo possa ser mediado, é necessário que uma das partes, pelo menos, tenha um conflito de ódio, amor ou de dor. (WARAT apud MENEZES, 2001, p. 63)

Por fim, a conciliação trata do método no qual as partes agem na composição com intermédio de um terceiro, o conciliador. Esta se diferencia da mediação no quesito subjetivo, pois necessita de um terceiro judicial, enquanto aquela carece de um terceiro de fora do processo. Além disso, a conciliação, levando em conta a formalidade, ocorre em um processo judicial, o que significa que pode ser parcialmente ou integralmente desfeito (SENA, 2007, p. 98).

Com base nesses métodos de heterocomposição, tem-se os núcleos de assistência jurídica das instituições de ensino de Direito, que buscam a resolução de conflitos por meios menos desgastantes, preferencialmente, sem recorrer ao Poder Judiciário, para as classes menos favorecidas financeiramente. Estes institutos atendem questões especificas e possuem em suas instalações espaços de mediação para a melhor solução do conflito original, sem que haja muito atrito entre as partes.

Outra modalidade alternativa de resolução de conflitos que vem ganhando força no âmbito jurídico nacional é a Justiça Restaurativa, que se apresenta como alternativa à pacificação de conflitos penais. Construídos a partir de uma visão crítica da ineficiência sistema punitivista, os métodos restaurativos buscam a construção de uma justiça baseada na resolução dos conflitos, por meio da exclusão do seu efeito que estigmatiza e exclui o autor de um ilícito penal, buscando o diálogo e o respeito aos direitos fundamentais, com a participação, quando conveniente e possível, da comunidade, de forma que de promove o empoderamento dos envolvidos no conflito e a pacificação social. Sua idealização traz consigo uma mudança paradigmática, ao modificar a forma de compreensão do fenômeno criminoso, que passa a ser percebido como um conflito intersubjetivo inerente ao contexto das relações sociais.

Página 163 Caderno de Ciências Sociais Aplicadas, Vitória da Conquista/BA, vol. 15, n 26, ano 15, p. 151-167, jul/dez 2018. 


\section{Considerações finais}

Muito se evoluiu e se vem evoluindo ao longo da história jurídica e social, porém, determinados comportamentos e ideias persistem enraizados em nosso sistema. Apesar das garantias e seguranças previstas pelo Estado Democrático de Direito, muitos aspectos não são levados a efeito, omissões estas que atuam como verdadeiros obstáculos à efetivação da Justiça.

A sociedade é posta em uma posição distante da justiça, tanto na idealização dos meios de resolução de conflitos, quanto no momento de sua efetivação, quando deveria ser justamente o oposto, pois a justiça deve ser pautada no reflexo das demandas sociais, focando nos reais destinatários das consequências das práticas legislativas e judiciais. Faz-se absolutamente necessária a aproximação da justiça aos valores culturais locais e à efetivação dos Direitos Humanos consagrados.

Portanto, esta aproximação deve ser concretizada por meio do fomento à adoção de mecanismos alternativos de resolução de conflitos, que é de notória importância para que determinados obstáculos sejam superados, como a morosidade processual, o abuso de poder de profissionais jurídicos, o alto custo do pleito, além da geração de uma sensação de pertencimento da comunidade em relação à Justiça.

Necessita-se da disseminação da importância da participação cidadã somada à difusão do conhecimento relacionado aos direitos das pessoas, despertando o seu interesse. Dessa forma, notar-seá maior envolvimento da comunidade em diversos espaços, como audiências públicas, e na fiscalização e reivindicação dos seus direitos, afinal, uma sociedade empoderada pelo conhecimento é nascedouro da mais genuína manifestação de Justiça.

Os obstáculos apresentados no texto que são a linguagem inacessível, falta de educação e conhecimento, juntamente com a falta de assistência, alto custo processual, morosidade processual e escassez de efetivos são alguns dos fatores que ocasionam a obstrução do acesso à Justiça, sendo necessária a utilização de mecanismos que busquem solucionar tal problema.

Assim, faz-se indispensável o emprego de meios alternativos e extrajudiciais de solução de conflitos, tais como a arbitragem, conciliação, mediação e Justiça Restaurativa, que são meios menos formais e procedimentais, consequentemente menos custosos, sem ou com menor morosidade e com maior facilidade de compreensão por parte população menos favorecida economicamente e educacionalmente, devido à maior informalidade, ao se comparar com o processo judicial.

Página 164 Caderno de Ciências Sociais Aplicadas, Vitória da Conquista/BA, vol. 15, n² 26, ano 15, p. 151-167, jul/dez 2018. 


\section{Referências}

ARISTÓTELES. Ética à Nicômaco. Trad. Leonel Vallandro e Gerd Berheim. São Paulo. Nova Cultural: 1996.

BONAVIDES, Paulo. Do estado liberal ao estado social. 8. ed. São Paulo: Saraiva, 2007.

BRASIL, Deilton Ribeiro. A Justiça Segundo Aristóteles.Universo Jurídico, Juiz de Fora, ano XI, 27 de fev. $\quad 2002.2$ de Disponível em: <http://uj.novaprolink.com.br/doutrina/1120/a_justica_segundo_aristoteles $>$ Acesso em fev. de 2018.

BRYCH, Fabio. O ideal de Justiça em Aristóteles. Âmbito Jurídico, Rio Grande, IX, n. 36, jan2007.. Disponível em: <http://www.ambitojuridico.com.br/site/index.php?n_link=revista_artigos_leitura\&artigo_id=1613>. Acesso em fev. de 2018.

CAPPELLETTI, Mauro; GARTH, Bryant. Acesso à justiça. Trad. Ellen Gracie Northfleet. Porto Alegre: Sergio Antonio Fabris, 1998.

CARVALHO, Luiz Fernando Ribeiro de. Democracia e acesso à justiça. Revista da

EMERJ, $\quad$ v.1, n.1. $1998 . \quad$ Disponível em: <http://www.emerj.tjrj.jus.br/revistaemerj_online/edicoes/revista01/revista01_161.pdf> Acesso em fev. de 2018.

CERQUEIRA, Társis Silva de. Acesso à justiça: novíssima reflexão. GAJOP, Justiça Cidadã. Disponível em: <http://gajop.org.br/justicacidada/wp-content/uploads/ACESSO-\%C3\%80-JUSTI\%C3\%87A.NOV\%C3\%8DSSIMA-REFLEX\%C3\%83O.pdf>. Acesso em fev. de 2018.

GALANTE, Carlos Eduardo da Silva. O acesso à justiça como princípio do estado democrático de direito. INESUL<https://www.inesul.edu.br/revista/arquivos/arq-idvol_33_1431715429.pdf >. Acesso em fev. de 2018.

GALVÃO, Eliane Santos; et al. Por que o conceito de justiça de Hans Kelsen confunde-se com a ética? Boletim Jurídico. $2006 . \quad$ Disponível em: <http://www.boletimjuridico.com.br/doutrina/texto.asp?id=1323>. Acesso em fev. de 2018.

GRAU, Eros Roberto. O direito posto e o direito pressuposto. 4. ed. São Paulo: Malheiros, 2002.

JUNQUEIRA, Eliane Botelho. Acesso à Justiça: um olhar retrospectivo. Revista Estudos Históricos, n.18, 1996. Disponível em: <http://www.egov.ufsc.br/portal/sites/default/files/anexos/25477-25479-1PB.pdf>. Acesso em fev. de 2018.

Página 165 Caderno de Ciências Sociais Aplicadas, Vitória da Conquista/BA, vol. 15, n² 26, ano 15, p. 151-167, jul/dez 2018. 
MINGATI, Vinícius Secafen; RICCI, M. M. D. S. Conceito de acesso à justiça: a efetividade do processo como garantia de acesso a uma ordem jurídica justa. UENP. Disponível em: $<$ http://eventos.uenp.edu.br/sid/publicacao/artigos/1.pdf>. Acesso em fev. de 2018.

MORAES, Ricardo Quartim de. A evolução histórica do estado liberal ao estado democrático de direito e sua relação com o constitucionalismo dirigente. Revista de informação legislativa, out./dez. 2014. n. 204, ano $51 . \quad$ Disponível em: <https://www2.senado.leg.br/bdsf/bitstream/handle/id/509938/001032358.pdf?sequence=1>. Acesso em: fev. 2018.

NAVES, Nilson Vital. Acesso à justiça. Pronunciamento proferido na abertura do Seminário em Belo Horizonte/MG em 24/04/2003. Disponível em: <http://bdjur.stj.jus.br/jspui/bitstream/2011/1052/Acesso_\%20\%C3\%A0_\%20Justi\%C3\%A7a.pdf> . Acesso em fev. de 2018.

OLIVEIRA, Aline Santos; et al. Acesso à Justiça. FAIT Revista. 2015. Disponível em: $<$ http:// fait.revista.inf.br/imagens_arquivos/arquivos_destaque/pItTNezwtbykS71_2015-1-29-21-1642.pdf>. Acesso em fev. de 2018.

PINHEIRO, Armando Castelar. Judiciário, reforma e economia: a visão dos magistrados. IPE A. Rio de Janeiro, julho de $2003 . \quad$ Disponível em: <http://www.ipea.gov.br/portal/images/stories/PDFs/TDs/td_0966.pdf>. Acesso em fev. de 2018.

SÁ, Eduardo Bruno do Lago de. Acesso à justiça e juizados especiais civeis. UNB (monografia). Brasília. 8 de julho de 2011. Disponível em: <http://bdm.unb.br/bitstream/10483/1823/1/Monografia_Eduardo_Bruno_do_Lago_de_Sa.pdf>. Acesso em fev. de 2018.

SILVA, José Afonso da. Curso de direito constitucional positivo. 16. ed. São Paulo: Malheiros, 1999.

SANTOS, José Alealdo dos. O princípio do acesso à justiça no direito brasileiro. Jusbrasil. Disponível em: <https://alealdolewandowski.jusbrasil.com.br/artigos/271966906/o-principio-do-acesso-a-justicano-direito-brasileiro>. Acesso em fev. de 2018.

SOUZA, Luciane Moessa. Mediação de conflitos: novo paradigma de acesso à justiça. Esserenel Mondo, UFSC, Florianópolis, dezembro de $2010 . \quad$ Disponível em: < https://repositorio.ufsc.br/bitstream/handle/123456789/94327/292011.pdf?sequence=1 >. Acesso em fev. de 2018.

STRECK, Lenio Luiz; MORAIS, José Luiz Bolzan de. Ciência politica e teoria geral do estado. 4. ed. Porto Alegre: Livraria do Advogado, 2004.

SENA, Adriana Goulart de. Forma de Resolução de Conflitos e Acesso à Justiça. Rev. Trib. Reg. Trab. $3^{\text {a }}$ Reg., Belo Horizonte, v.46, n.76, p.93-114, jul./dez.2007. Disponível em <https://juslaboris.tst.jus.br/bitstream/handle/1939/73935/2007_sena_adriana_formas_resolucao.pd esequence $=1$ \&isAllowed $=\mathrm{y}>$ Acesso em fevereiro de 2018 .

Página 166 Caderno de Ciências Sociais Aplicadas, Vitória da Conquista/BA, vol. 15, n² 26, ano 15, p. 151-167, jul/dez 2018. 
WARAT, Luís Alberto. Ecologia, psicanálise e mediação. Trad. Julieta Rodrigues, Porto Alegre: Sérgio Antônio Fabris, 1995.

Recebido em maio de 2018

Aprovado em outubro de 2018

Página 167 Caderno de Ciências Sociais Aplicadas, Vitória da Conquista/BA, vol. 15, n 26, ano 15, p. 151-167, jul/dez 2018. 